\title{
Aircraft Gas Turbine Engine Vibration Diagnostic
}

\author{
Stanislav Fabry ${ }^{1 *}$, Marek Ceskovic ${ }^{2}$
}

\author{
${ }^{1}$ Department of Aviation Engineering, Faculty of Aeronautics, Technical University of Košice, Košice, \\ Slovak Republic \\ ${ }^{2}$ Department of Avionics, Faculty of Aeronautics, Technical University of Košice, Košice, Slovak Republic \\ *Corresponding author: Technical University of Košice, Faculty of Aeronautics, Department of Aviation \\ Engineering, Rampova 7, 04121 Kosice, Slovak Republic, Email: stanislav.fabry@tuke.sk
}

\begin{abstract}
In the Czech and Slovak aviation are in service elderly aircrafts, usually produced in former Soviet Union. Their power units can be operated in more efficient way, in case of using additional diagnostic methods that allow evaluating their health. Vibration diagnostics is one of the methods indicating changes of rotational machine dynamics. Ground tests of aircraft gas turbine engines allow vibration recording and analysis. Results contribute to airworthiness evaluation and making corrections, if needed. Vibration sensors distribution, signal recording and processing are introduced in a paper. Recorded and re-calculated vibration parameters are used in role of health indicators.
\end{abstract}

\section{Keywords}

Diagnosis - Engine - Health indicators - Rotor vibration

\section{Introduction}

Aircraft gas turbine engine (AGTE) is the most frequently used power unit of an aircraft. It enables moving of aircraft on the ground and flying in the atmosphere. It must not spontaneously stop, power (thrust) lowering, unwanted behavior occurring during the flight or taxiing (oscillation, noise growth). Huge vibrations and big noise can inappropriately or seriously influence aircrew, aircraft systems, instruments, etc. Vibration motion results in dynamic load of structure. Its growth can cause fast deterioration, fatigue cracks formation, and consequently premature failure.

It is not possible to avoid mechanical oscillations in the technical praxis. Specialist estimating importance of oscillation manifestation, issues from the need of machine reliable performance. Every assembled machine has unique vibration signature, when it works [1]. The changes of this signature in time indicate abnormal behav- ior or structural stiffness changes. Changes of vibration allow revealing changed health of machine [2].

\section{Aircraft Gas Turbine Engine Vibration Hazardousness}

Internal and external sources of AGTE vibrations were introduced in many publications. Internal sources of vibrations manifest at engine run. This is connected with engine design, assembly and its structure properties. Influence of environment, near surroundings (wind blasts, rudder flatter, etc.), as well as working processes of engine and aircraft equipment (pulsation of fuel delivery, pumps rotation, etc.) can be considered to be external sources.

Engine and its near surrounding consist of numbers of vibration generators and resonators that attenuate or amplify transferred mechanical oscillations. Commonly, the vibration is continually attenuated with distance from the source. 
Amplitude and finite number of oscillation allowable during life cycle are in relation with Wöhler curve. This is important for high-cycle fatigue of metal engine parts, composite, rubber and plastic structure. Structure withstands many repetitions at small amplitude, without failure. Cracks spread/extensions are connected with continual „tiredness“ of a material. This causes consequent concentration of stress, but also change of elasticity and material damping [3].

Abnormalities and irregularities of system performance influence dynamics of machine behavior. Size and weight of detected problem evaluation depends on its principle of birth, on its manifestation and on measurement method.

A complicated machine as an AGTE is possible to consider as a set of resonators. This point of view is used due to vibrations frequency content evaluation. Whole energy of vibrations is not important in such model of engine. Only energy consumed by resonators is interesting. Those vibrations are more dangerous, which energy is concentrated in one or more narrow bands around resonant frequencies. It means that at acting of poly-harmonic vibration on simple resonator is powerful enough only in a case when resonance is considered only at main component of oscillations with the biggest amplitude (close to the resonant frequency). The last claim seems to be too complicated. Everything is clear after imagination of reaction that is frequency dependent. It needs not to be necessarily the first harmonic of some vibration source that excites resonator. It can be some of harmonic components, instead.

Engine failure can be, among others, caused by any of the reasons [4]:

- bearing damage/fault,

- equipment driving fault,

- blade/vane grid damage - when material freed from broken part is carried by gas stream and causes consequent damages.

Some of introduced phenomena develop for longer time. The reason can be, for example, crack "breathing", cyclic deformation, repeated (over)heating, rotor speed acceleration and deceleration, etc.

\section{Components with Bearing Frequencies in the Spectrum of Vibrations}

Monitoring of rolling bearing vibrations is generally possible only on bearing house. It can be distinguished between three stages of bearing life. Let us consider bearing to be perfect, immediately after production and trial run. This first stadium can last for relatively long time, in case of right operation and maintenance.

Beginning of wear or fault development starts the second stage. Fault development can be slow, in case of right using (loading) of a bearing. Vibrations of bearing components copy trend curve [5]. Slow development of wearing is guided with small variance of vibration parameters. Components are visible only when using special methods developed for rolling bearing diagnostics.

Growth of variance and quantities them self indicates serious development of fault. It indicates the third stage. Bearing components start to be visible in the spectrum of vibrations measured on the bearing house [6].

When vibrations are measured far from bearing housing, there is small probability of bearing frequency components visibility. If some occurs, particular part is in unsatisfactory condition - it is very close to failure.

With aim to detect the second (it means an earlier) stage of fault development, it is suitable to implement special methods, as for example, enveloping of filtered signal. It is not guaranteed, but more probable, that in the spectrum of enveloped signal will be visible bearing fault component with small amplitude, what indicates fault development. Growth of this component during the flight hours depends on the fault development, on the signal transfer path properties and on distance from the bearing to the sensor.

Vibration specialist has to take into account that signal measured on the body of engine may not be corresponding its origin. The path between source (vibrating part) and the sensor influences it. The main task of vibration diagnostics is to monitor changes in signals, not absolute values.

Bearing frequencies are important indicator of health of engine shaft support. Their occurrence in spectrum of enveloped signal indicates the second stage of wear/fault development. Bearing frequencies occurrence in spectrum of raw signal indicates the third - dangerous development stage.

\section{Driving of Aggregates}

Gas turbine necessarily need for their performance lubrication and cooling of kinematic couples, fuel supply, working regimes control. Pressure and sucks pumps, regulators, speed sensors and other equipment are driven from an engine shaft(s) [7]. They have almost the same importance, as above mentioned bearings. Their faults are, by experiences, developed continuously and they are early detectable by debris monitoring and vibration measurement. There is a cut of turbo-shaft engine in the figure 1 for making imagination about engine moving parts assembly.

The engine is two spool, having aggregates above and below air intake. Both parts of driving gearbox are driven by vertical shafts. The picture allows making review of engine main parts. This is the starting point for vibration sensors distribution around engine case.

This type of engine was monitored by ground vibration measurements during the first author's active duty in 


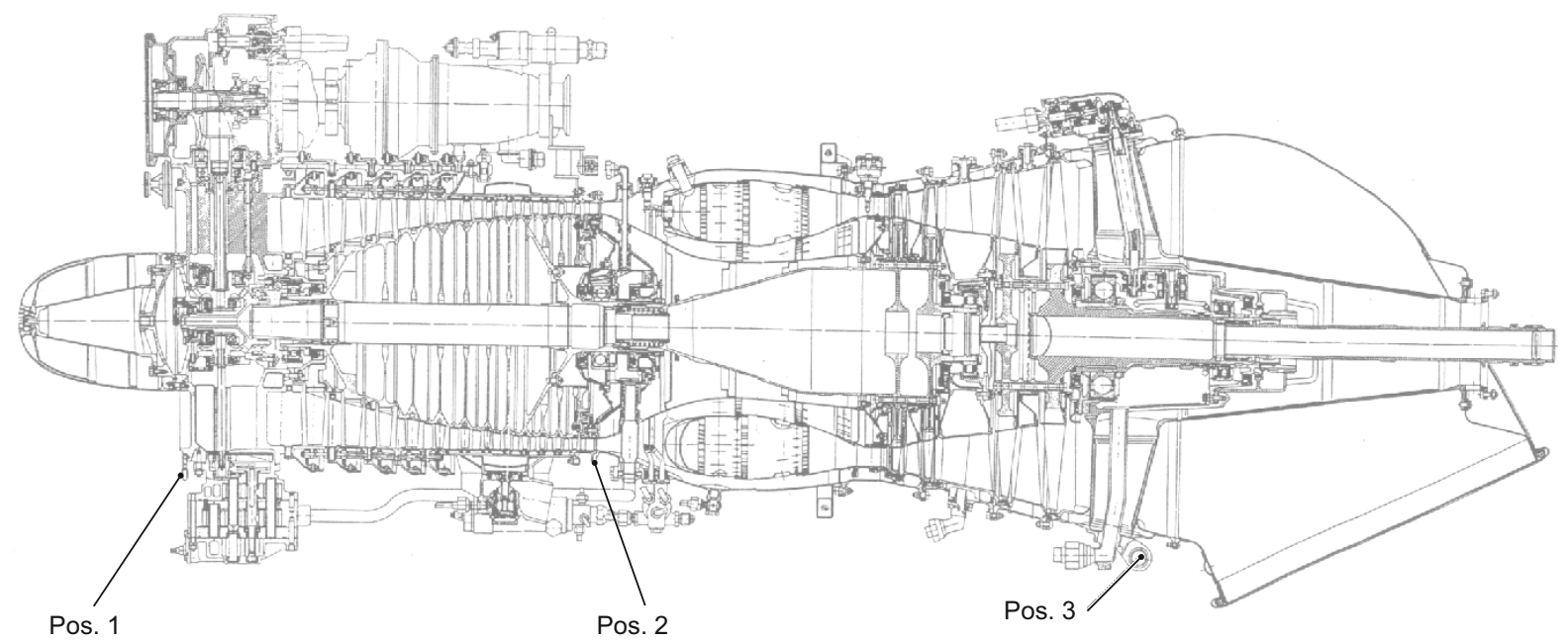

Figure 1. Cut of TV3-117 helicopter engine

Slovak Air Forces. Sensors were mounted before testing. The same measurement setup has been used for all tests. Results of recordings were compared and evaluated.

\section{Blade Grids of Compressor and Turbine}

Single blades/vanes or whole/completed stages are threatened mostly by solid material intrusion from atmosphere. Grains of sand do not damage them immediately, but long term abrasion results in damage. Bigger pieces usually threat the first stages. It can be detected early, because they are well accessible for visual inspections. Following compressor and turbine stages are controllable through visual inspection holes. This check can be done during maintenance.

Vibration diagnostics of higher compressor stages that have large number of small vanes, needs larger frequency range. Higher sampling frequency together with requirement of high resolution leads to big size of files, where measured data are recorded. In such case, utilization of visual inspections is better solution, than vibration monitoring [8].

\section{Rotor Vibrations}

Gas turbine changes ongoing during the time of duty can lead to decreasing of rotating mass by singe, melting, breaking, etc., or to increasing by pollution, soot, welding of material occurring in hot gas stream, etc. It leads to changes in engine main shaft balance. Unbalance is not dangerous, until it reaches standardized value according to ISO 1940. However, the higher unbalance is harmful for shaft support (it means bearings).

Rotor vibrations can have many harmonics. They excite vibrations of surrounding components. If some harmonic has frequency close to natural frequency of engine component, resonance can occur.
Shaft vibrations absolute size evaluation is possible according to engine producer directions for operation. When there is known mass of rotor, then technical standard can be implied, in the meaning of rigid rotor balance criteria. In some cases, elastic shaft supports are used in aircraft gas turbine. Then, vibrations are not standardized. If there are used rigid shafts and elastic bearings (engine RD-33 used in an airplane Mig-29), measured vibrations are not fully relevant. Anyway, if huge amplitudes occur in recorded signals, there exists some problem (powerful source or booster) and it should be solved.

It is recommended, to involve into evaluation, analysis of shaft vibration closest divisional frequency components $(1 / 2 \times f)$ and multiple frequency components $(2 \times f$, $3 \times f)$. Origin of these vibrations should be clear from the results (their existence versus amplitude). Usually it is non-sinusoidal moving of shaft.

Vector summarization of vibrations can highly load supporting components that transfer forces. Therefore investigation them and their (sub)harmonics is important.

It is also possible to compare vibrations with unbalance allowed by standard ISO 1940 for category G 6.3 - aircraft engine rotor assembly. It can be done on the basis of knowledge of shaft mass and engine speed. Measurement has to be made at under-critical regime. It means regime without resonance and/or shaft and bearing elasticity influence.

\section{Engine Health Indicators}

Relations between vibration signal properties and engine health are expressed by health symptoms or indicators. Symptoms can be signal parameters itself, quantities calculated from raw signal and/or re-calculated signal. Time signal waveform is meant as a raw signal. 


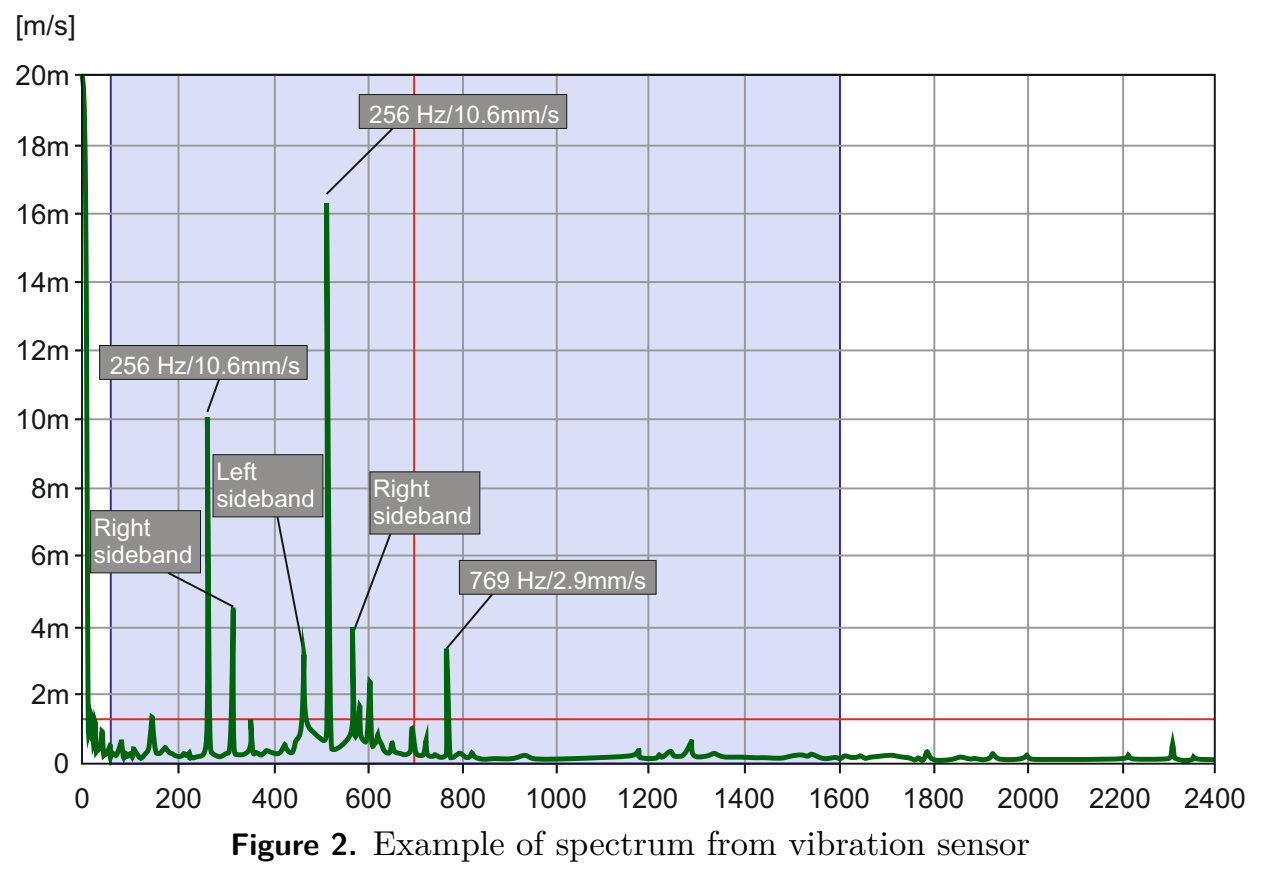

Some kind of instrumentation gives direct transformation to the frequency domain in real time during measurement. Original signal from accelerometer is acceleration, and it is disadvantage that any integration and/or differentiation introduce some signal deformation.

Basically, vibration velocity (acceleration integrated in the time) represents good correlation to energy carried by vibration motion. However, vibration acceleration can disclose some phenomena that are non-visible in signal of velocity. Both quantities are useful in complex approach to vibration analysis. Particular technique prefers one of these parameters.

Main rotor assembly is the biggest rotating mass of gas turbine. This one loads all engine parts by vibrations. The most important factor of dynamic loads directly acting on main bearings is rotor unbalance. The most important symptom is amplitude of the first harmonics of the main rotor (there are also two- or three-spool engines).

The first harmonics is a signature of vibration motion of any else process in an engine. Therefore it is used as a main symptom for particular phenomenon. Other symptoms can be used as supporting. They can be used as a main in case of special method that is based on specific behavior of machine or structure. Example of set of symptoms is introduced in table 1.

A TV3-117 gas turbine vibrations measured by sensor in position 3 (see Fig. 1) in axial direction are shown in figure 2. The spectrum contains three harmonics of free turbine rotor plus their sidebands in distance of $51 \mathrm{~Hz}$ far from central frequency components. Some other peaks are visible.
Table 1. Review of vibration parameters usable as health indicators for gas turbine engine

\begin{tabular}{|c|c|c|}
\hline \multirow{2}{*}{ Parameter } & \multicolumn{2}{|c|}{ Category } \\
\hline & Key & Auxiliar \\
\hline $\begin{array}{l}\text { Amplitude of the main rotor first har- } \\
\text { monic }\end{array}$ & + & \\
\hline $\begin{array}{l}\text { Magnitude of band-pass vibrations } \\
\text { related to the main rotor }\end{array}$ & + & \\
\hline Important peak in spectrum & & + \\
\hline Sideband peak in spectrum & & + \\
\hline Peak in a cepstrum & & + \\
\hline Kurtosis & & + \\
\hline
\end{tabular}

Summary vibration velocity in frequency band 60$1600 \mathrm{~Hz}$ was calculated (the band is highlighted in the picture) by measurement software. The measurement was done in frequency range up to $6400 \mathrm{~Hz}$. However, region above $800 \mathrm{~Hz}$ seems to be not interesting/important.

\section{Conclusion}

AGTE vibration parameters can be used in role of health indicators. A spectral analysis is the most obvious approach, when specialist evaluates contribution of isolated frequency components and power in frequency regions to whole vibration energy that can damage engine structure. It can be supported by software application in Excel or MATLAB, where frequencies of rotating components are derived from main rotors speeds. Bandpass values are important due to overall vibration (dynamic) load evaluation. Suitable supporting parameters are useful, when significant phenomena occur in recorded signal. 
AGTE vibration diagnostics is well implemented in on-line complex diagnostic system. It can be improved by detailed vibration measurements during ground tests. Vibration is one of the best indicators of structure behavior during its duty.

\section{Acknowledgments}

The knowledge introduced in the paper could be collected thanks to solving several projects funded by NATO/STO. Their goals were development of advanced diagnostics based on vibration measurements.

\section{References}

[1] B. Rao. Profitable Condition Monitoring. Springer Netherlands, Dordrecht, 1993. ISBN 9789401116169.

[2] S. Fábry and A. Kelbel. Design criteria for vibration diagnostics of a jet gas turbine engine, 2012.

[3] C. Cempel. Limit value in the practice of machine vibration diagnostics. Mechanical Systems and Signal Processing, 4(6):483-493, Nov 1990. doi: 10.1016/ 0888-3270(90)90047-o. URL http://dx.doi.org/ 10.1016/0888-3270(90)90047-0.
[4] R. Andoga, L. Madarász, L. Fozo, T. Lazar, and V. Gašpar. ACTA POLYTECHNICA HUNGARICA, 10(5), Sep 2013. doi: 10.12700/ aph.10.05.2013.5.5. URL http://dx.doi.org/ 10.12700/APH.10.05.2013.5.5.

[5] T. Gałka. Vibration-based diagnostics of steam turbines. In Mechanical Engineering. InTech, 2012.

[6] A. Mironov, P. Doronkin, A. Priklonskiy, and S. Yunusov. Adaptive technology application for vibration-based diagnostics of roller bearings on industrial plants. Transport and Telecommunication Journal, 15(3), Jan 2014. doi: 10.2478/ttj-2014-0021. URL http://dx.doi.org/10.2478/ttj-2014-0021.

[7] A. Poullikkas. An overview of current and future sustainable gas turbine technologies. Renewable and Sustainable Energy Reviews, 9(5):409-443, Oct 2005. doi: 10.1016/j.rser.2004.05.009. URL http://dx.doi.org/10.1016/j.rser.2004.05.009.

[8] R Mobley. Plant engineer's handbook. ButterworthHeinemann, Boston, 2001. ISBN 9780080539041. 